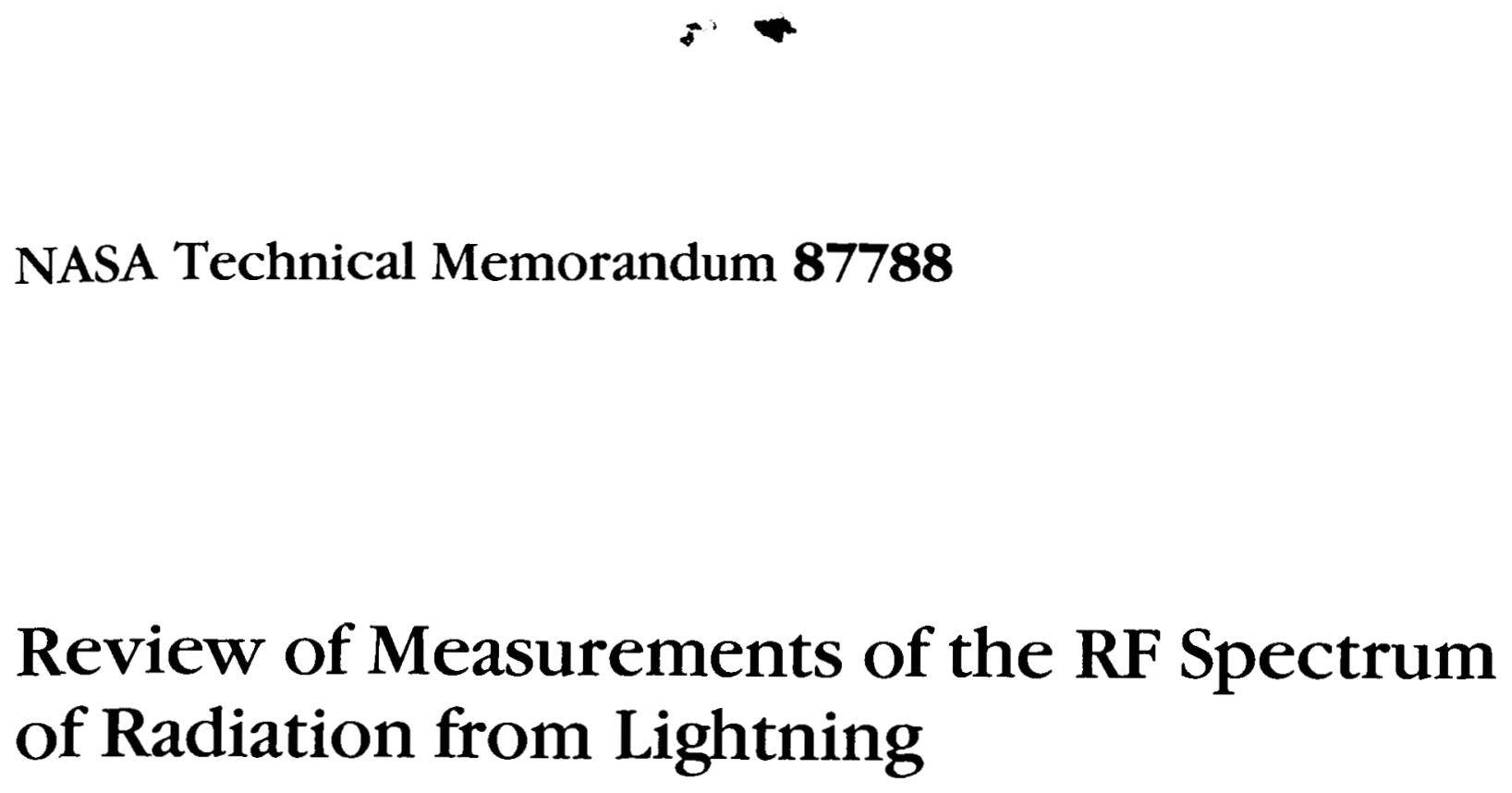

\title{
Review of Measurements of the RF Spectrum of Radiation from Lightning
}

David M. Le Vine

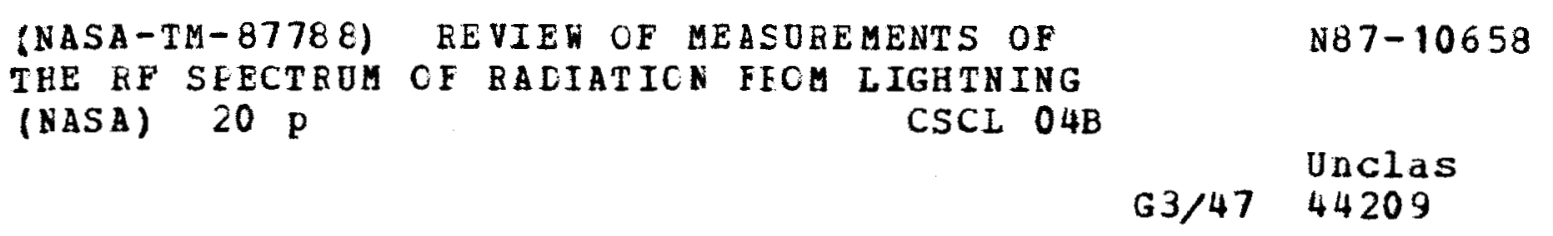

MARCH 1986 
NASA Technical Memorandum 87788

\section{Review of Measurements of the RF Spectrum of Radiation from Lightning}

David M. Le Vine

Laboratory for Oceans

Microwave Sensors and Data Acquisition Systems Branch

Goddard Space Flight Center 


\section{INTRODUCTION}

The electromagnetic radiation from lightning at microwave frequencies and below is generally referred to as the "radio frequency" or "RF" portion of the spectrum. Radiation from lightning in this portion of the spectrum is important both for scientific investigations of lightning and for engineering assessments of the interference environment during thunderstorms. Measurements have been reported from frequencies below a kilohertz to frequencies above a gigahertz.

The word "spectrum" is generally used in the literature on lightning in this frequency range to mean the magnitude of the Fourier transform of the electric field $E(t)$ radiated during the discharge. In applications to lightning, two methods have traditionally been employed to measure this spectrum. In one, the spectrum is obtained from the electric field waveform itself by Fourier transforming. The electric field waveform is recorded first using instrumentation such as a fast field change system and wide bandwidth recorder, and the spectrum is obtained numerically from this record by means of a Fourier transform. This technique has the appeal of being straight forward, but it requires wide bandwidth recording devices with large dynamic range because the power at high frequencies tends to decrease rapidly with frequency. The second technique is to measure the energy radiated at a particular frequency directly using a filter and detector system tuned to the frequency of interest. Standard radio receivers suitable for this purpose are available in this frequency range. The major difficulty with measurements of this type has been in identifying the element of the lightning flash (e.g., leader, return stroke, etc.) which is the source of the radiation. Each of these techniques will be described in this report and a summary given of the data obtained with each.

\section{SPECTRA OBTAINED BY FOURIER TRANSFORM}

A lightning flash is not a single event but, rather, is a sequence of many discrete events. Some, such as return strokes and the leader steps preceeding a first return stroke, have received much attention and are reasonably well known, whereas others such as the many different events which take place in the cloud are only recently beginning to be studied. The electric fields radiated from these events tend to have characteristic (time domain) shapes which permit the events to be identified and spectra to be obtained separately for the various events.

For example, at the top in Figure 1 is shown an electric field waveform $E(t)$ recorded by the author in Florida during the Thunderstorm Research International Project (TRIP; Pierce, 1976). This waveform has a shape characteristic of those observed during first return strokes (Uman and Krider, 1982; Weidman and Krider, 1978). It begins abruptly with a rapid rise to peak and then decays irregularly toward zero. Frequently, the abrupt beginning is preceeded by a string of small pulses associated with the stepped leader (Krider et al., 1977; Weidman and Krider, 1980). The last such step is visible in this record just before the beginning of the return stroke. The graph at the bottom of Figure 1 is the magnitude of the Fourier transform of the waveform, E(t), shown at the top. The Fourier transform was obtained numerically after the waveform at the top was digitized.

Figure 2 shows the results of averaging waveforms from 20 return strokes. The data was recorded in Florida during a short period of strong activity associated with a nearby thunderstorm on July 20,1976 . At the top is the average of the time domain electric field waveforms, $\mathrm{E}(\mathrm{t})$, and at the bottom is the average of the magnitude of the Fourier transform (the magnitudes were averaged). This data was collected by the author during TRIP-76.

One of the earliest applications of the Fourier transform approach was made by Watt and Maxwell (1957). In the course of describing measurements of low frequency attenuation due to the earth, they made Fourier transforms of electric field waveforms recorded by Norinder (1954) and Florman (1955) and from them formed a composite spectrum; however few details were given regarding the waveforms. Later, Taylor (1963) reported a carefully documented measurement of the spectrum in which the lightning discharges were located and propagation losses 

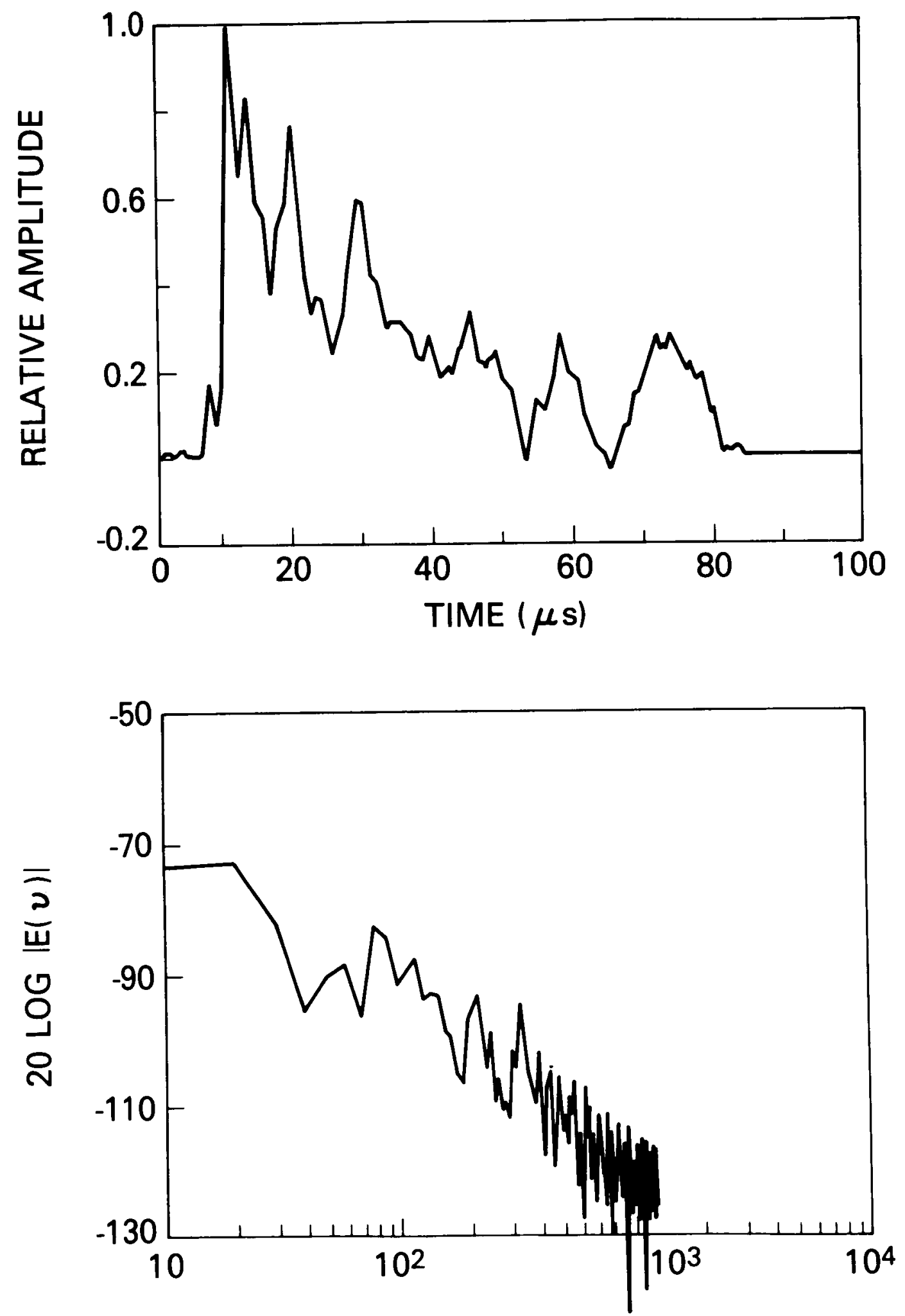

FREQUENCY (kHz)

Figure 1. Electric field waveform (top) and its Fourier transform (bottom) for a first return stroke. Recorded in Florida during TRIP-76. 

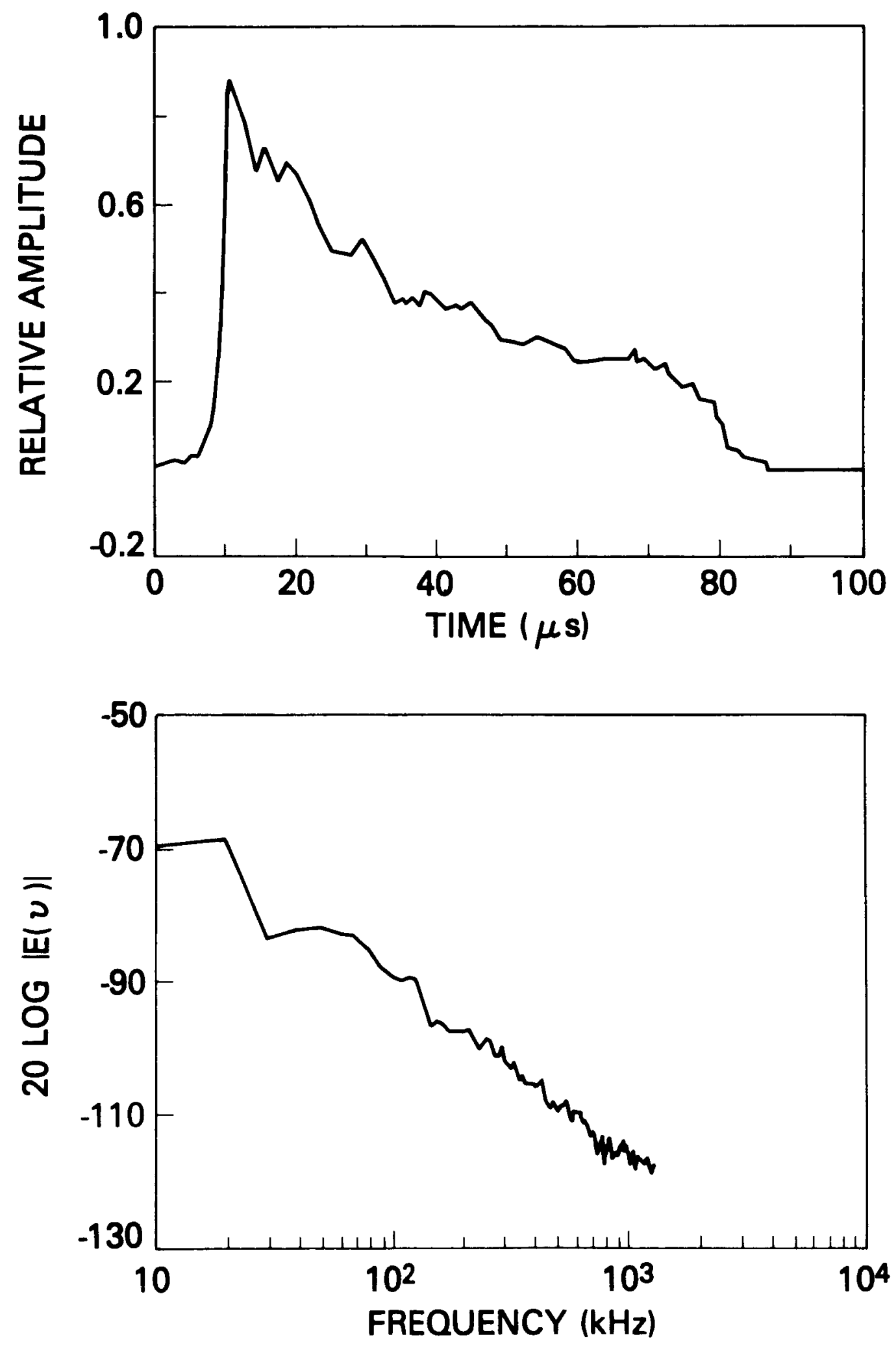

Figure 2. Average electric field waveform (top) and average magnitude of the Fourier transform of the individual waveforms (bottom). Data recorded from first retum strokes in Florida during TRIP-76. 
taken into account. Taylor recorded return stroke waveforms and made Fourier transforms over a frequency range from $1-100 \mathrm{kHz}$. The spectrum he obtained is shown in Figure 3 (open circles) normalized to a range of $50 \mathrm{~km}$. The normalization has been done assuming a (distance) ${ }^{-1}$ dependence for the amplitude. The spectrum obtained by Taylor peaks near $5 \mathrm{kHz}$ and then decays roughly as (frequency) ${ }^{-1}$ to $100 \mathrm{kHz}$, the limit of the measurements. In obtaining this spectrum, Taylor used the recently verified theory for the effects of attenuation due to propagation over the earth to correct for the loss of signal at low frequencies. He had both this theory and tools for locating the lightning discharge at his disposal.

The Fourier transform approach was largely ignored until Serhan et. al., (1980) again reported spectra of radiation from return strokes. Using modern techniques for locating nearby return strokes (Krider et. al., 1976; Krider et. al., 1980), Serhan et. al. were able to separate first and subsequent return stroke waveforms and compute spectra for each. Their data for first return strokes at $50 \mathrm{~km}$ are shown in Figure 3. These data fit well with Taylor's (1963) measurements and extend the (frequency) ${ }^{-1}$ trend to several hundred kHz. The spectra obtained by Serhan et. al. (1980) for subsequent return strokes has substantially the same shape but is somewhat lower in amplitude.

Weidman et. al., (1981) using substantially similar techniques also reported spectra of first return strokes (squares in Figure 3). Their data, collected from lightning over the ocean to minimize effects of propagation, extend the spectrum to $1 \mathrm{MHz}$ and continue to show a decrease proportional to (frequency) ${ }^{-1}$.

Weidman et. al., (1981) also reported first return stroke spectra at higher frequencies which they obtained by recording the derivative, $\mathrm{dE} / \mathrm{dt}$, of the electric field waveform rather than $\mathrm{E}(\mathrm{t})$ itself. Recording the derivative improves the sensitivity of the measurement to higher frequencies (because the spectrum of the derivative is the spectrum of the waveform multiplied by frequency). The data obtained by Weidman et. al., (1981) in this manner are shown with solid triangles in Figure 3. Notice that the data show a decrease with frequency which is greater than the (frequency) $)^{-1}$ decrease characteristic of the data at lower frequencies. The Weidman et. al., (1981) results were obtained using only the first few microseconds of the radiation waveform. Since, this portion of the waveform is most strongly affected by propagation losses, it is not clear whether the rapid decrease evident in the data is a real characteristic of first return strokes or an artifact of the measurements. On the other hand, there is some theoretical evidence to suggest that a decrease in the spectrum as (frequency) ${ }^{-2}$ should manifest itself at high frequencies (Le Vine, 1980).

A few measurements using the Fourier transform approach have been made of the spectrum of events other than return strokes. All of these have been reported recently by Weidman, et. al., (1981). Figure 4 shows the spectra obtained for positive (top) and negative (bottom) intracloud events. The curves show the spectra of the intracloud events superimposed on the spectrum of first return strokes (solid line). On the left in Figure 4 are examples of positive and negative intracloud events recorded by the author (Le Vine) at the Goddard Space Flight Center, in Greenbelt, Maryland in 1982. Notice that at the high frequencies the spectra for these events tend to coincide with the spectrum of return strokes, but at low frequencies the spectrum is smaller than the spectrum of return strokes and decreasing. This is the behaviour one would expect of a discharge with the same general physical characteristics as a return stroke but of shorter length (e.g. Le Vine, 1980).

\section{SPECTRA FROM DIRECT MEASUREMENT}

In addition to the approach described above, it is also possible to determine the spectrum directly by measuring the power incident at a particular frequency. The procedure is to use a filter to accept signals only in a narrow band of frequencies near the one of interest and then to use a detector to measure the power being radiated in this frequency band. The precise relationship between the spectrum at the nominal frequency, $v_{\mathrm{o}}$, to which the filter is tuned and the output from this system depends on the specific filter and detector employed. An important special case occurs when the filter is very narrow (a small percentage of the center frequency, $v_{\mathrm{o}}$ ) and the detector is an 


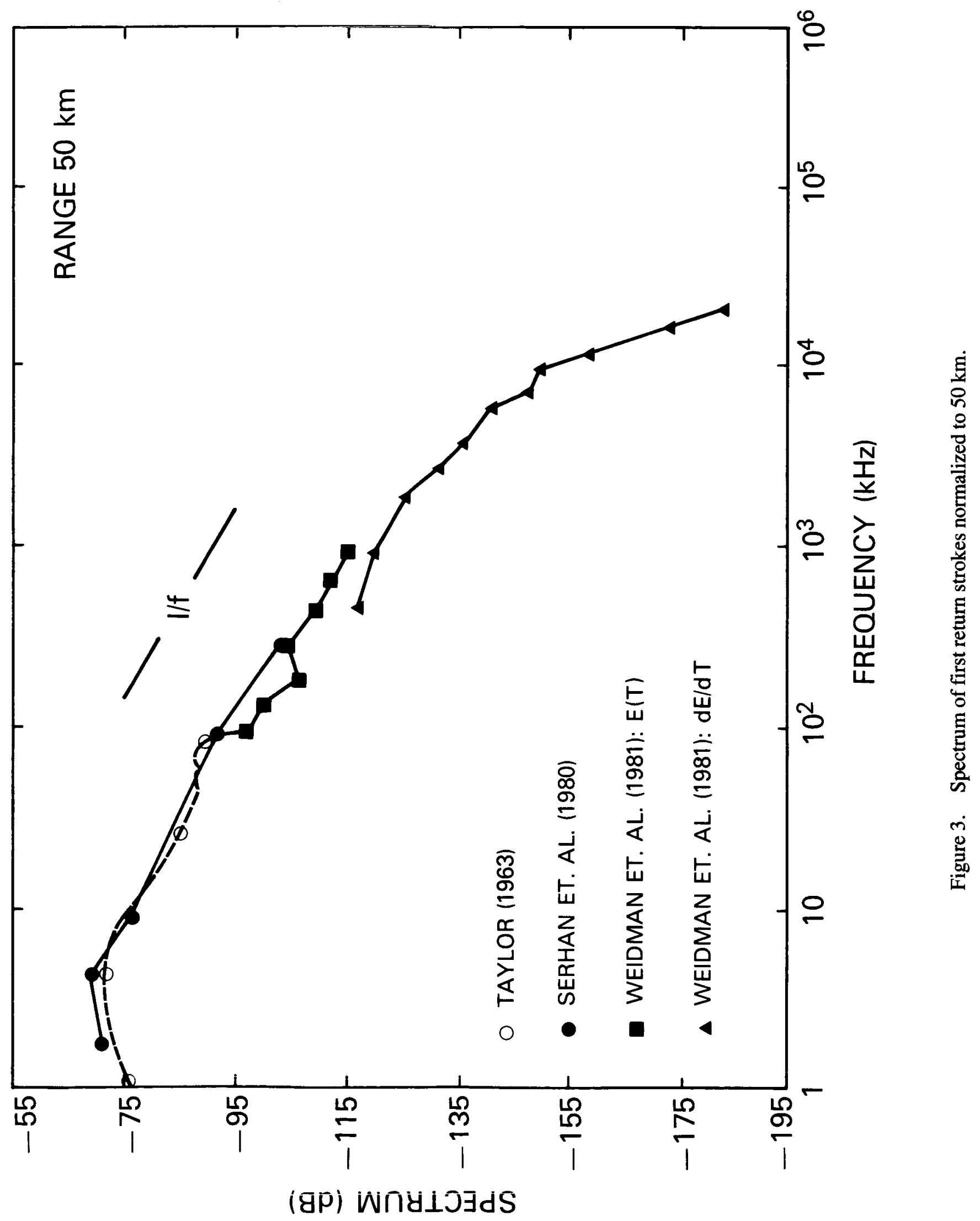




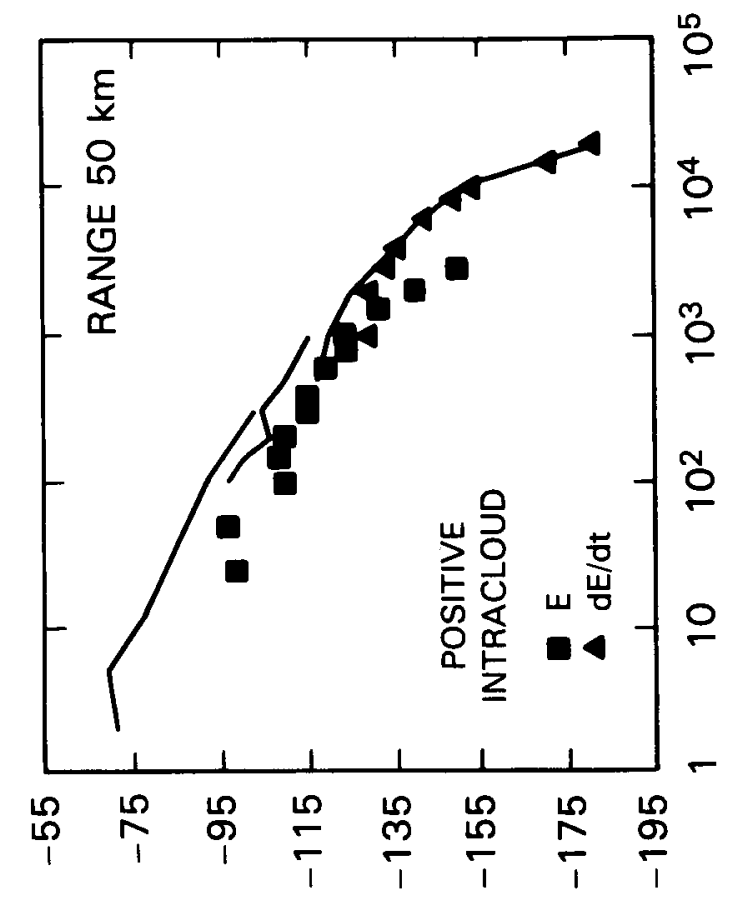

(gp) wกy

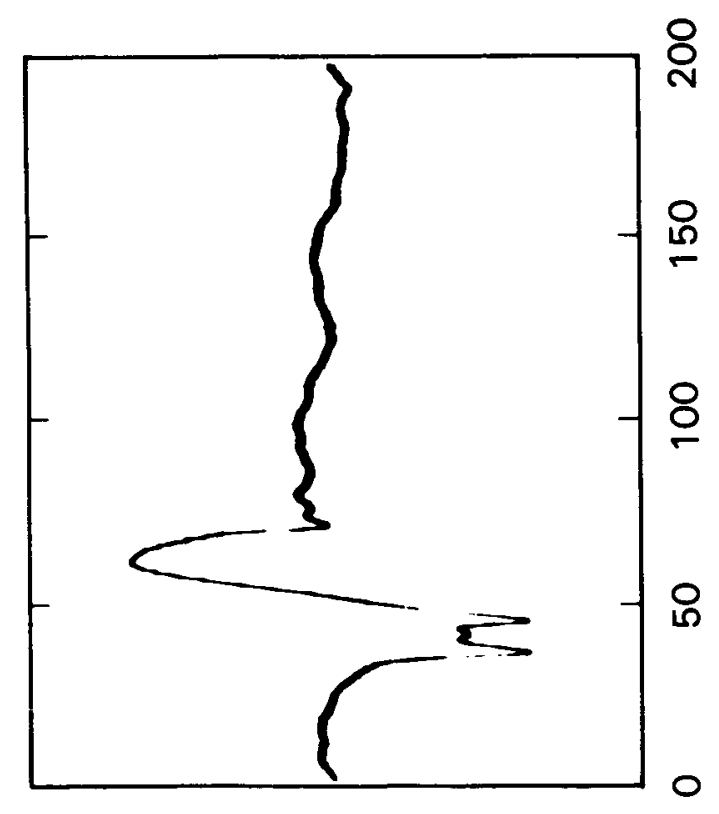

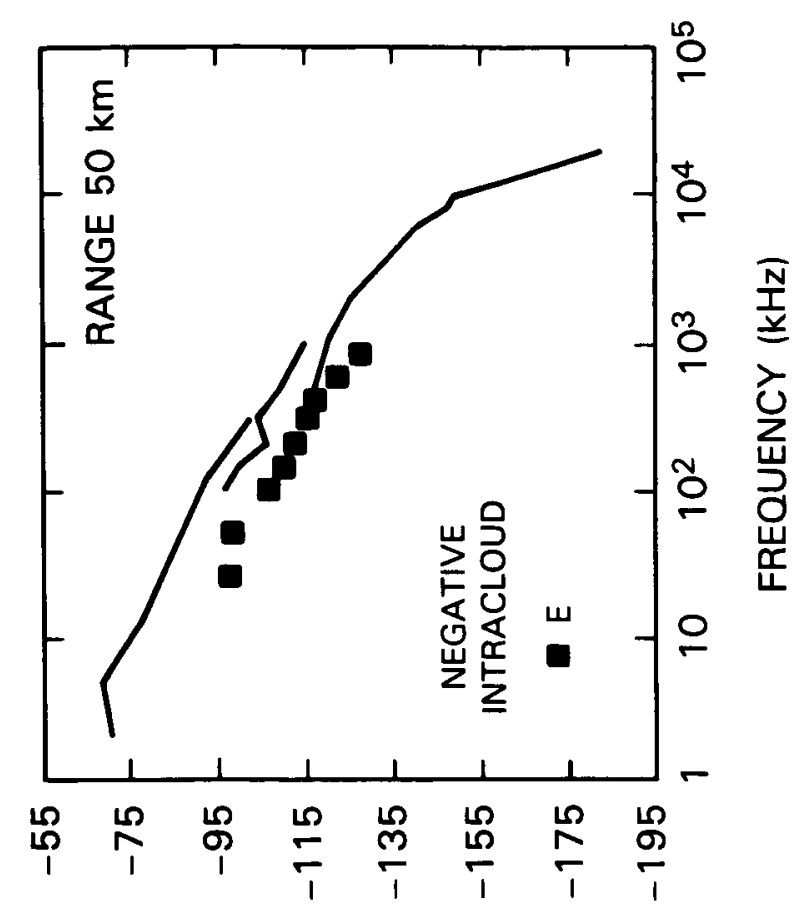

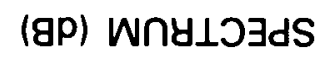

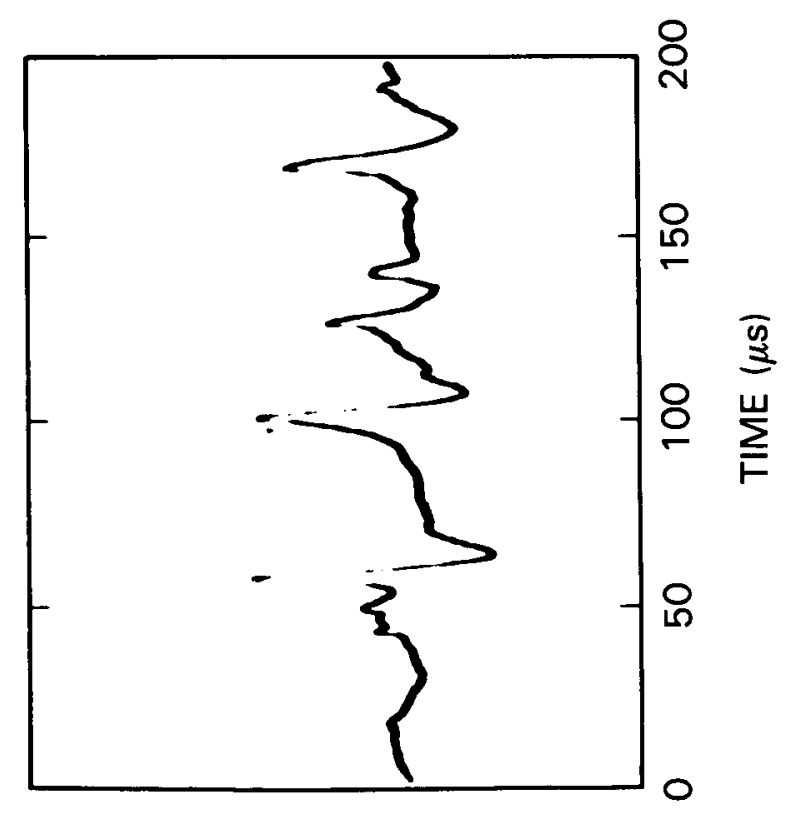

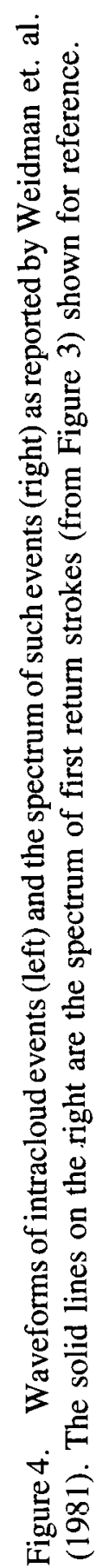


envelope detector of the type employed in conventional AM radio receivers. In this case, if the input is a single impulse, the spectrum $\mathrm{S}\left(v_{\mathrm{o}}\right)$ is proportional to the peak value, $\mathrm{e}_{\mathrm{p}}$, of the output. This relationship is derived in Appendix $A$ where it is shown that with an ideal bandpass filter of bandwidth $B$ and system gain $G$ one obtains:

$$
\mathrm{S}\left(v_{\mathrm{o}}\right)=\frac{\mathrm{e}_{\mathrm{p}}}{2 \mathrm{~GB}}
$$

Data obtained using this technique are illustrated in Figure 5. The amplitude of the spectra have been normalized to lightning at $50 \mathrm{~km}$ using (distance) ${ }^{-1}$ as the rule for scaling amplitude and (bandwidth) ${ }^{-1}$ as the rule for converting from peak field measurements to spectra when necessary (Equation 1). Among the earliest measurements of this type are those of Schafer and Goodall (1939) who were interested in assessing the potential interference lightning presented for transmission of television signals. Their data at $139 \mathrm{MHz}$ is shown with a solid triangle in Figure 5. Extensive measurements over a wide range of frequencies were made by Horner and Bradley (1964). These data are shown with the solid line in Figure 5. Additional measurements by Kosarev et. al., (1970) and in 1963 by Hallgren and McDonald (adapted from Cianos, Oetzel and Pierce, 1972) are also shown in Figure 5. The spectrum which emerges from these measurements is one which peaks near $5 \mathrm{kHz}$ and then decreases as $1 / \mathrm{f}$ to the limits of the measurements $(1 \mathrm{GHz})$.

The preceeding are only some of the measurements which have been made with this technique. A large number of measurements have been made, but under a great variety of circumstances (e.g., distance, type of receiving equipment and bandwidth). It is often difficult to reduce the measurements to common units. Nevertheless, several attempts have been made to combine the measurements by normalizing the data to common bandwidth and distance (e.g., Horner, 1964,; Oh, 1969; Kimpara, 1965; Cianos, Oetzel and Pierce, 1972). Additional data gathered from these reviews are plotted in Figure 6. The relationship (distance) ${ }^{-1}$ has been used to convert to lightning $50 \mathrm{~km}$ away and the relationship (bandwidth) $)^{-1}$ has been used to convert peak field measurements to spectra (Equation 1). Shown with open circles are data by Takagi and Takeuti (1963) as reported by Kimpara (1965). Data by Iwata and Kanada (1967) as reported by Cianos, Oetzel and Pierce (1972) are shown with X's. Finally, measurements of several researchers using radar receivers (Atlas, 1959; Hewitt, 1957; Pawsey, 1957) as reported by Oh (1969) and Cianos, Oetzel and Pierce (1972) are shown with open triangles. Notice that these additional data tend to fall somewhat below the 1/f spectrum suggested in Figure 5 and with a significart spread of the data, especially at the higher frequencies.

A major problem faced in interpretating spectra such as presented in Figures 5 and 6 is that the data do not represent radiation from single events (e.g. return strokes) but rather represent some generally unknown collection of events in the flash. To illustrate the nature of the problem, the output from several AM radio receivers as seen during a representative cloud-to-ground lightning flash is shown in Figure 7. The records at 3, 30 and $300 \mathrm{MHz}$ are data from real lightning recorded by the author in Florida during the Thunderstorm Research Project (TRIP-76; Pierce, 1976) using standard AM radio receivers with a common bandwidth of $300 \mathrm{kHz}$. The records at 30 and 300 $\mathrm{kHz}$ are the author's impression of what radiation from the flash would look like based on reports in the literature (e.g., Horner and Bradley, 1964; Malan, 1958). The slow electric field change for this flash is shown at the bottom for reference. Notice that the radiation consists of many discrete impulses. Some of the impulses correlate with identifiable portions of the discharge. For example, the initial impulses in this record occur where one expects to find the stepped leader, and the return strokes (which occur at the abrupt changes in the slow electrical field change record) are associated with large impulses of RF radiation. However, these are only a few of the impulses seen during the flash. The others are probably associated with intracloud portions of the discharge about which we have only begun to learn. The discrete nature of the radiation is characteristic of the data recorded by this author from both cloud-to-ground and intracloud discharges (e.g., Le Vine, 1976). Another important characteristic of the data is that the radiation does not appear to change from a series of discrete impulses at the lower frequencies to a continuum at the higher frequencies as reported in some investigations (e.g., Horner and Bradlcy, 1964; Míalain, 1958). Rather the radiation consists of a sequence of discrete impulses at all frequencies in the range $(3-300$ $\mathrm{MHz}$ ) investigated by this author. In addition, the impulses tend to correlate well among the frequencies. That is, a 


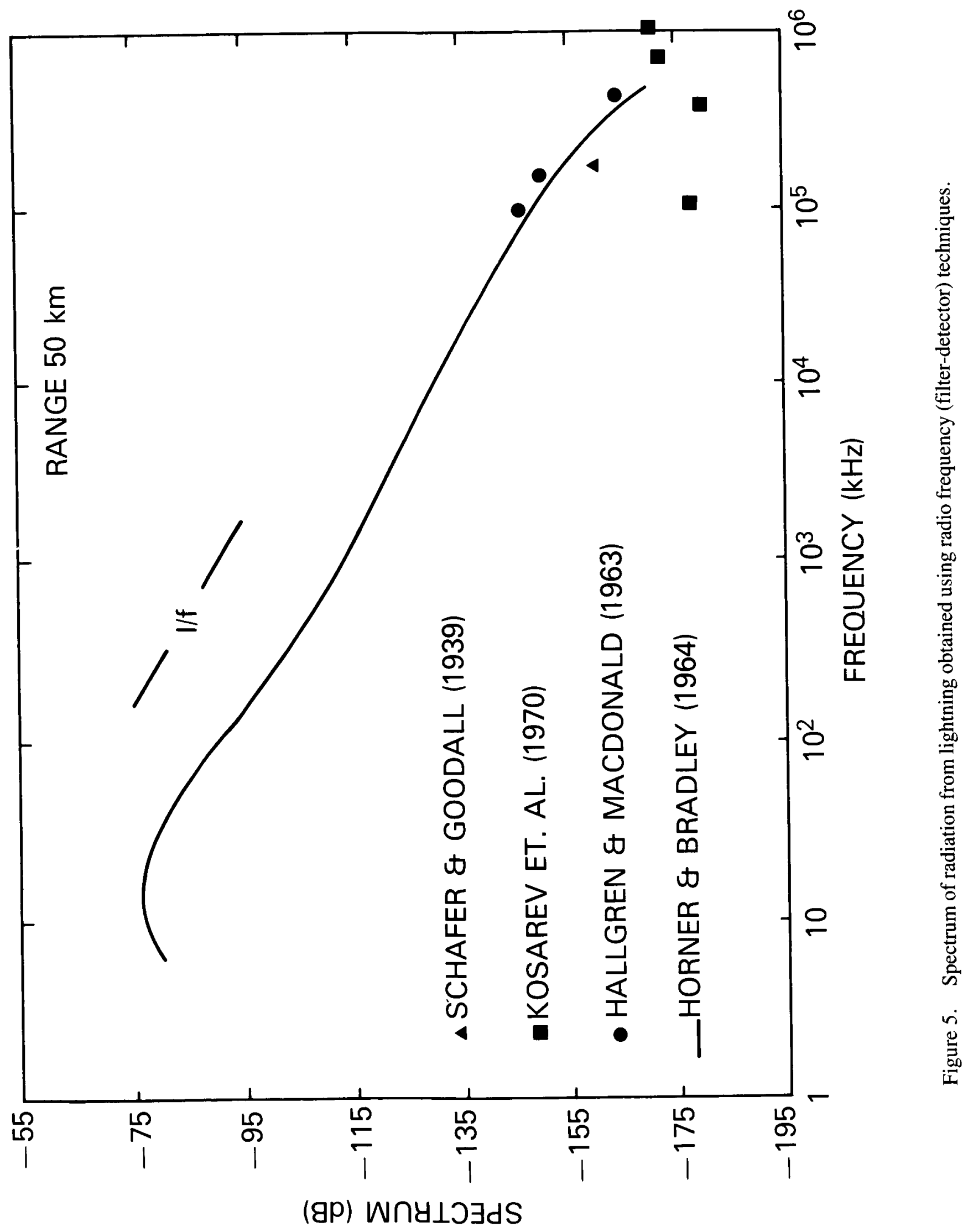




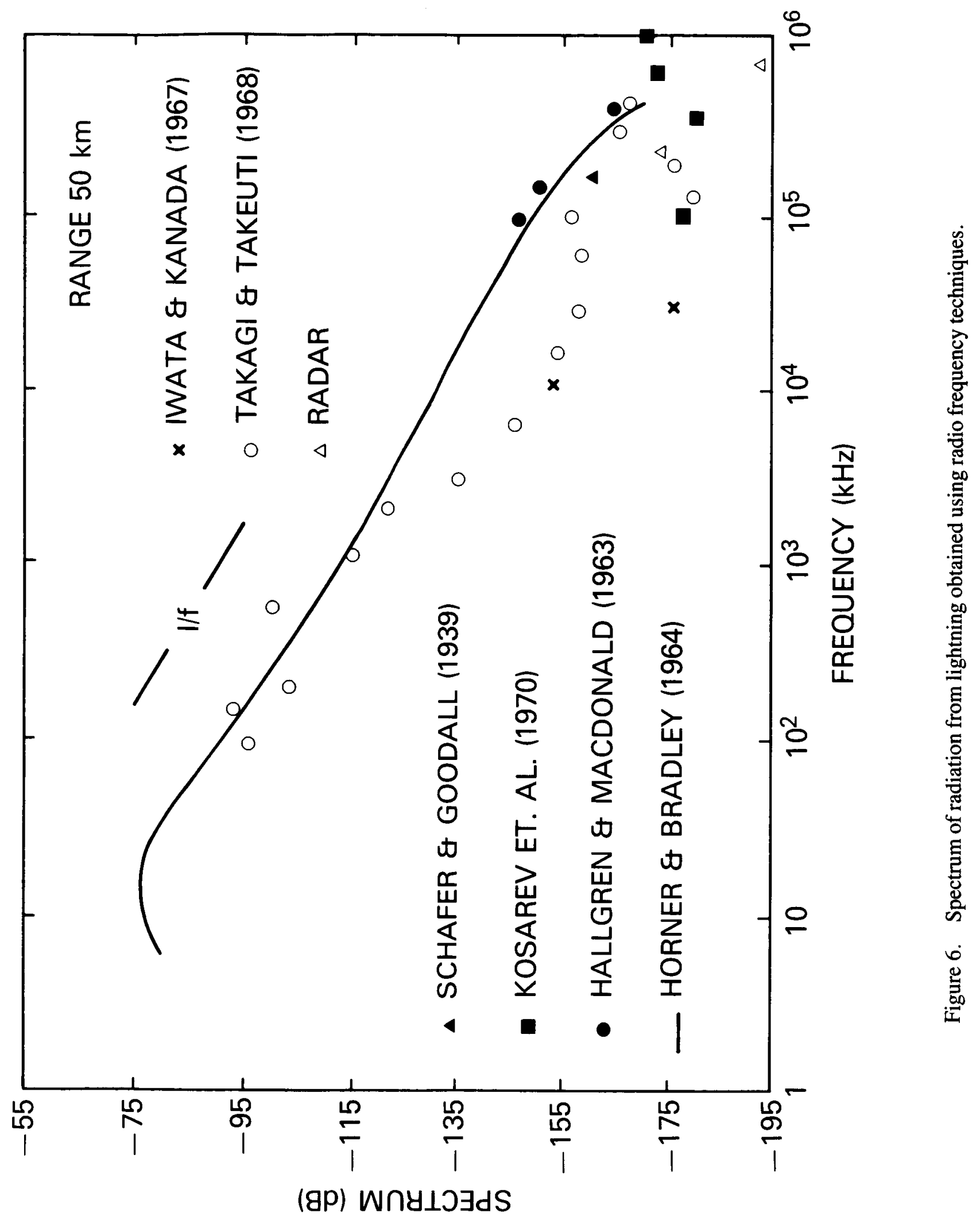




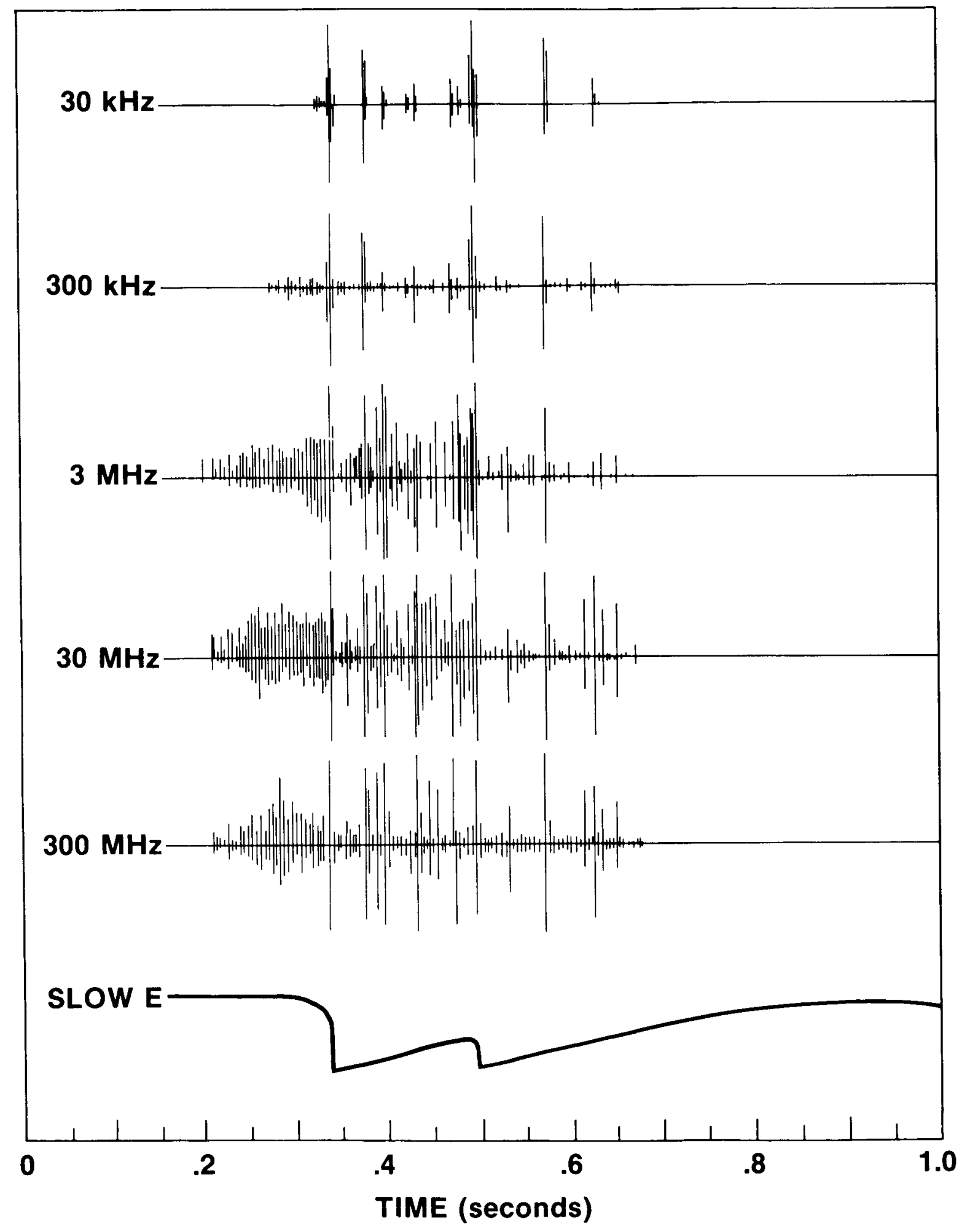

Figure 7. Radiation from a cloud-to-ground lightning flash. The signals at 3-300 MHz are data recorded by the author. The examples at 30 and $300 \mathrm{kHz}$ are an estimate based on measurements reported in the literature. 
particular impulse tends to be present at all frequencies. The behaviour is consistent with a lightning flash consisting of a sequence of individual discharges (leader steps, return strokes, K-changes, etc.) each radiating over a very broad band of frequencies. Certainly the return stroke is a discharge with this characteristic (Figure 3).

The problem which occurs with spectral measurements using the filter-detector approach is distinguishing between impulses. The impulse response of the measuring system is inversely proportional to the system bandwidth; consequently there exists a fundamental contradiction between the requirement for a bandwidth narrow enough to be close to the nominal frequency of interest and the ability of the measurement to distinguish between closely spaced impulses. For example, with a bandwidth of $250 \mathrm{~Hz}$, the impulse response of the system is on the order of 0.25 seconds. This would include many impulses in a typical lightning discharge (Figure 7). Very few investigators have attempted to distinguish between events with measurements of this type and those who have tried have had difficulty (e.g., Takagi and Takeuti, 1963). The spectra which have been reported using this method generally must be regarded as an integral (average) over many events in the flash. The exception is at VLF frequencies where, because of the low frequency, return strokes tend to be the dominant source of radiation.

\section{DISCUSSION}

Notice the similarity between the spectrum of the first return stroke (Figure 3 ) and the composite spectrum obtained from all the filter-detector measurements (Figures 5 and 6). To facilitate the comparison, the spectra have been plotted together in Figures 8 and 9. Figure 8 shows the return stroke spectrum (Figure 3 ) and the spectrum in Figure 5 together, and Figure 9 shows the return stroke spectrum and all the filter-detector measurements (Figure 6) together. Considering all the variables that enter such measurements, the spectra are very similar. This is especially so at frequenices below $1 \mathrm{MHz}$, but even at higher frequencies where the spread in the data is great, the two spectra overlap.

The similarity between the spectra is not surprising because of any fundamental difference between the two techniques. In fact, in principle the two techniques for measuring the spectrum of lightning discharges ought to yield identical results. In practice, they should be complimentary, the Fourier transform approach having advantages at low frequencies and the direct (filter-detector) approach having advantages at higher frequencies. However, because of the relatively narrow bandwidth employed, the filter-detector technique does not measure radiation from a single event, but rather is an average over many events in the flash. Furthermore, the data in Figures 5 and 6 were obtained from measurements of different bandwidth and without any attempt at identifying the portion of the flash monitored. Consequently, it would seem reasonable to assume that Figures 5 and 6 are more representative of the composite flash rather than of any particular event. What is surprising, then, is that the spectrum of the composite flash and the spectrum of one particular event, the return stroke, are so similar.

The similarity between the spectrum of one event, the return stroke, on the one hand, and what probably represents the spectrum of the composite flash on the other hand, suggests to this author a physical process common to all the various individual discharges which make up the lightning flash. There is some additional evidence supporting this view. For example, Weidman, et. al., (1981) measured spectra of intracloud processes and stepped leaders, and these tend to fall on the spectra for return strokes (Figure 4). The difference is a roll- off at the low frequencies which is to be expected for identical discharges of shorter length. Also, Le Vine $(1976,1980)$ has been able to predict spectra for the return stroke and composite flash which agree with measurements by assuming a transmission line model common to all events. (The events differ in such parameters as channel length, peak current and tortuosity.)

A critical test of this hypothesis occurs at high frequencies where all events should behave similarly. But this is where the data is most scattered. Consequently, it would seem important to obtain reliable spectral measurements of individual events at frequencies above a few $\mathrm{MHz}$. This would resolve the ambiguities in the spectral shape apparent in Figures 5 and 6 and would add insight into the physics of the lightning discharge. 


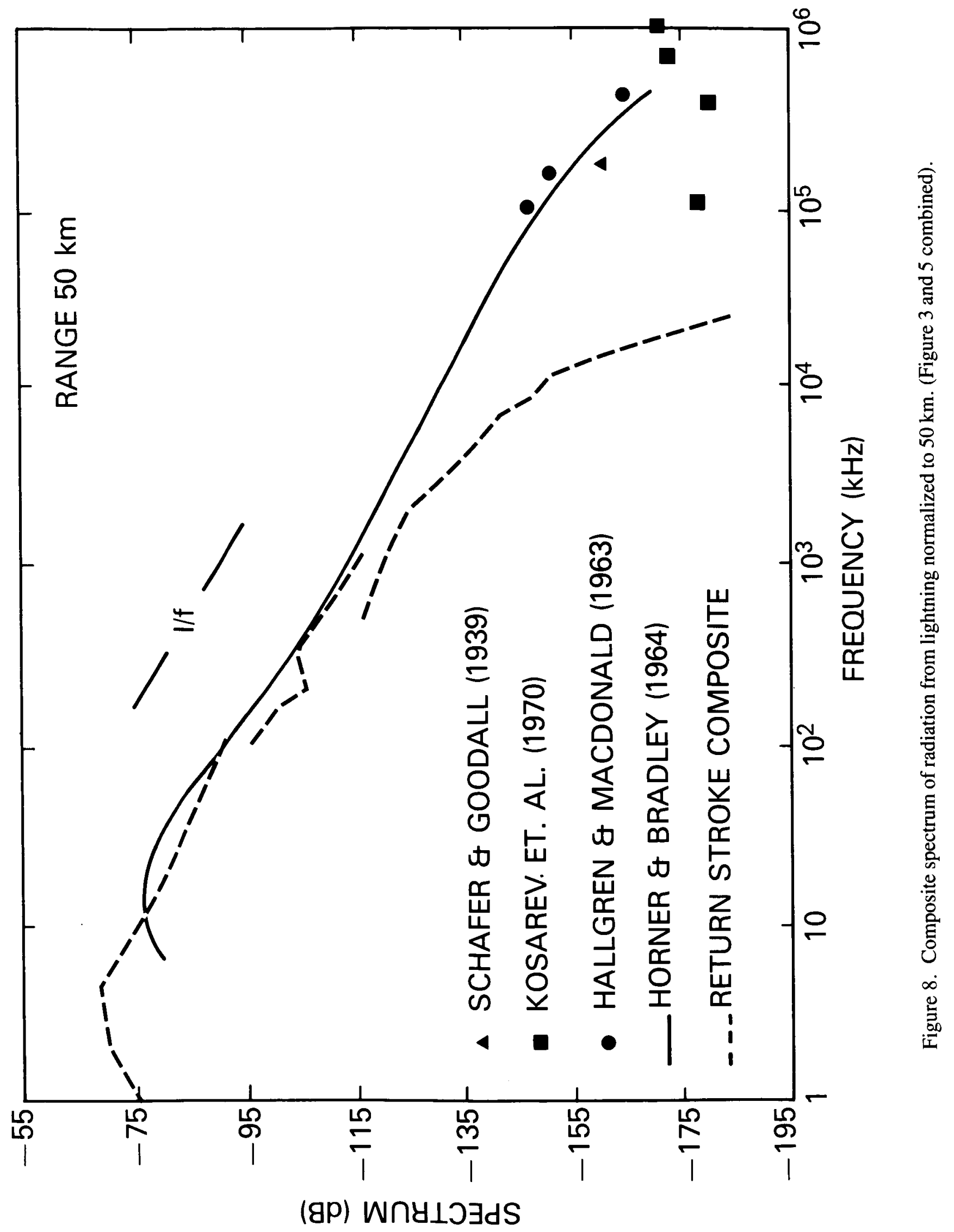




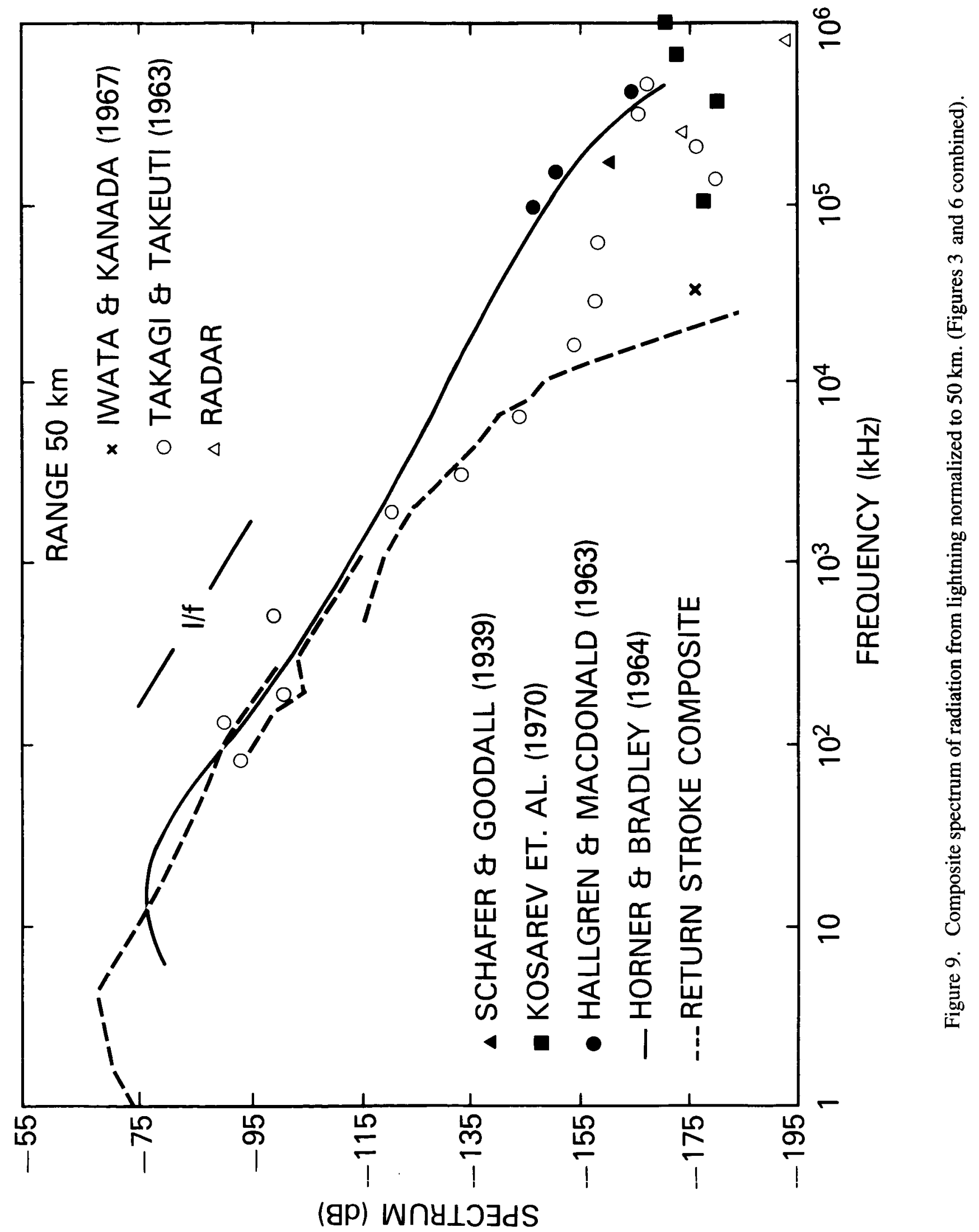




\section{REFERENCES}

Atlas, D. "Radar Lightning Echoes and Atmospherics in Vertical Cross Section," in Recent Advances in Atmospheric Electricity, L. G. Smith, ed. New York: Pergamon Press, 1959, pp. 441-458.

Born, M., and E. Wolf, “Principles of Optics,'” Pergamon Press, 1959.

Cianos, N., G. N. Oetzel and E. T. Pierce, "Structure of Lightning Noise - Especially Above HF,' Lightning and Static Electricity Conference, Wright Patterson AFB, December 1972.

Dennis, A. S., and E. T. Pierce, "The Return Stroke of the Lightning Flash to Earth as a Source of VLF Atmospherics,'” Radio Science, 68D (No. 7), pp. 777-794, 1964.

Florman, E. F., National Bureau of Standards Report \#3558, November, 1955.

Hallgren, R. E., and R. B. McDonald, “Atmospherics from Lightning from 100 to $600 \mathrm{MHz}$, Rep. No. 63538-89. IBM Federal Systems Division, 1963.

Hewitt, F. J., “'Radar Echoes from Interstroke Process in Lightning,'” Proc. Phys. Soc. London, 70, pp. 122204, 1957.

Horner, F., "Radio Noise from Thunderstorms,"' in Advances in Radio Research, Vol. 2, Academic Press, J. A. Saxton, ed., pp. 122-204, 1964.

Horner, F., and P. A. Bradley, "Spectra of Atmospherics from Near Lightning," J. Atmos, Terr. Phys., 26, pp. 1155-1166, 1964.

Kimpara, A., "Electromagnetic Energy Radiated from Lightning," in Problems in Atmospheric and Space Electricity, S. C. Coroniti, ed., Elsevier Pub. Co., pp. 352-365, 1965.

Kosarev, E. L., V. G. Zatsepin and A. V. Mitrofanov, "Ultrahigh Frequency Radiation from Lightning," J. Geophys. Res., 75(36), pp. 7524-7530, 1970.

Kraus, J. D., Radio Astronomy, McGraw-Hill Book Co., 1966.

Krider, E. P., C. D. Weidman, and R. C. Noggle, "The Electric Fields Produced by Lightning Stepped Leaders." J. Geophys. Res., 82, pp. 951-960, 1977.

Krider, E. P., R. C. Noggle and M. A. Uman, “A Gated Wideband Magnetic Direction-Finder for Lightning Return Strokes," J. Appl. Meteorol., 15, pp. 302-306, 1976.

Krider, E. P., R. C. Noggle, A. E. Pifer and D. L. Vance, "Lightning Direction-Finding Systems for Forest Fire Detection," Bull. Amer. Meteorol., Soc., 61(9), pp. 980-986, 1980.

Le Vine, D. M., et. al., "'The Structure of Lightning Flashes HF-UHF: September 12, 1975, Atlanta, Georgia, NASA X-953-76-176,1976.

Le Vine, D. M., "The Effect of Pulse Interval Statistics on the Spectrum of Radiation from Lightning," J. Geophys. Res. 82 (12), pp. 1773-1777, 1977. 
Le Vine, D. M., “'The Spectrum of Radiation from Lightning," Proc. IEEE International Symposium on Electromagnetic Compatibility, pp. 249-253, October 1980.

Malan, D. J., " Radiation from Lightning Discharges and its Relation to the Discharge Process,' in Recent Advances in Atmospheric Electricity, Proceedings of the 2nd Conference on Atmospheric Electricity, pp. 557-563, 1958.

Norinder, H., "'The Waveforms of the Electric Field in Atmospherics Recorded Simultaneously at two Distant Stations," Arkiv for Geofysik, 2 (9), pp. 161-195, November 1954.

Oh, L. L., "'Measured and Calculated Spectral Amplitude Distribution of Lightning Sferics,'” IEEE Trans., EMC-11 (4), pp. 2125-130, 1969.

Pawsey, J. L., “'Radar Observations of Lightning,'” J. Atmospheric Terr. Phys., 11, pp. 289-290, 1957.

Pierce, E. T., "'The Thunderstorm Research International Program (TRIP) - 1976,' Bull. Amer. Meteorol. Soc., 57,pp. 1214-1216, 1976.

Serhan, G. I., M. A. Uman, D. G. Childers, and Y. T. Lin, “The RF Spectra of First and Subsequent Lightning Return Strokes in the 1-200 km Range,"' Radio Sci., 15, pp. 1089-1094, 1980.

Schafer, J.P., and W.M. Goodall, "Peak Field Strengths of Atmospherics due to Local Thunderstorms at 150 Megacycles,” Proc. IRE, 27, pp. 202-207, 1939.

Takagi, M. and T. Takeuti, “Atmospherics Radiation from Lightning Discharge," Proc. Res. Inst. Atmos., Nagoya Univ., 10, 1963.

Taylor, W. L., 'Radiation Field Characteristics of Lightning Discharges in the Band $1 \mathrm{kc} / \mathrm{s}$ to $100 \mathrm{kc} / \mathrm{s}$,' J. Res. Nat. Bur. Stand., 67D, pp. 539-550, 1963.

Uman, M. and E. P. Krider, “A Review of Natural Lightning: Experimental Data and Modelling,' IEEE Trans. on Electromagnetic Compatibility, EMC-24 (2), pp. 79-112, 1982.

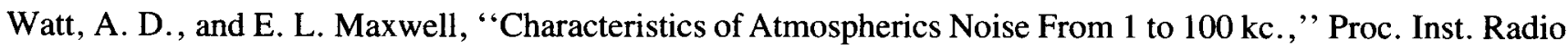
Eng., 45, pp. 787-794, 1957.

Weidman, C. D., and E. P. Krider, “'The Fine Structure of Lightning Return Strokes Waveforms, ' J. Geophys. Res. 83 , pp. 6239-6247, 1978.

Weidman, C. D. and E. P. Krider, "Submicrosecond Rise Times in Lightning Return Stroke Fields," Geophys. Res. Lettrs., 7, pp. 955-958, 1980.

Weidman, C. D., E. P. Krider, and M. A. Uman, "Lightning Amplitude Spectra in the Interval From $100 \mathrm{kHz}$ to $20 \mathrm{MHz}$,’ Geophys. Res. Lett., $\underline{8}$, pp. 931-934, 1981. 


\section{APPENDIX A}

\section{RADIO RECEIVER RESPONSE.}

It is the purpose of this appendix to derive an expression for the impulse response of an RF receiving system typical of the sort used to measure the spectrum of radiation from lightning. The system consists of an antenna, usually vertically polarized, connected to a standard AM radio receiver and followed with a post detection filter (Figure A1). Assuming that the antennas are vertically polarized and isotropic over the bandwidth of the measurements, they can be assumed to deliver a voltage proportional to the incident (vertical) electric field. Except for a phase which is ultimately lost in the detector, this proportionally constant is $\sqrt{\pi G / A_{e}} / k$ where $k=\omega \sqrt{\mu \epsilon}=2 \pi /$ $\lambda, G$ is the gain of the antenna in the plane parallel to the ground, and $A_{e}$ is the effective receiving area of the antenna (Kraus, 1966). The receiver is a device for detecting and amplifying the envelope of an amplitude modulated sinusoid (carrier) at a particular frequency. This is normally done by translating the input signal to an intermediate frequency where the actual processing is done. However, the frequency translation is done for engineering purposes to make the detection more efficient, and it is not necessary to do this in order to model the receiver output. The ideal device is a perfect envelope detector in series with a filter which represents the equivalent bandwidth and gain of the system.

For systems whose bandwidth $\delta$ is small compared to the nominal frequency, $v_{0}$, of the measurement, these operations can be written explicitly in terms of the Fourier transform of the incident radiation. To do so it is convenient to write the vertical component of incident radiation, $\mathrm{E}(\mathrm{t})$, in the form:

$$
E(t)=\operatorname{Re} \int_{0}^{\infty} 2 E(v) e^{-j 2 \pi v t} d v
$$

where Re means "real part of" and where $E(v)$ is the Fourier transform of $E(t)$. The integral is called the complex analytic representation of $E$ (t) (e.g., Born and Wolf, 1959). Using this notation, the signal V(t) out of the antenna and filter and into the envelope detector is:

$$
\mathrm{V}(\mathrm{t})=\operatorname{Re} \int_{0}^{\infty} 2 \mathrm{a}(v) \mathrm{H}(v) \mathrm{E}(v) \mathrm{e}^{-\mathrm{j} 2 \pi \nu \mathrm{t}} \mathrm{d} v
$$

where $H(\nu)$ is the Fourier transform of the filter $h(t)$ and $a(v)=(A / k) \sqrt{\pi G / A_{e}}$ is the combined effect of the antenna and an amplifier with gain, A. Although in practice the post detection filter is applied to the video output of the receiver, mathematically the effect of the post detection filter can also be included in $\mathrm{H}(v)$. This will be done here and it will be assumed that the equivalent filter $\mathrm{H}(v)$ has a passband centered about frequency $v_{\mathrm{o}}$ which is very narrow compared to $v_{o}$. That is:

$$
\mathrm{H}(v)= \begin{cases}\mathrm{H}\left(v-v_{\mathrm{o}}\right) & \left|v-v_{\mathrm{o}}\right|<\delta \\ 0 & \left|v-v_{\mathrm{o}}\right|>\delta\end{cases}
$$

and $\delta / \nu_{0}<<1$. Using this assumption and making the change of variables $\xi=v-\nu_{0}$, Equation A2 becomes

$$
\begin{aligned}
V(t) & =\operatorname{Re}\left\{\mathrm{e}^{-\mathrm{j} 2 \pi v_{\mathrm{o}} \mathrm{t}} \int_{-\infty}^{\infty} 2 \mathrm{a}\left(\nu_{\mathrm{o}}+\xi\right) \mathrm{E}\left(v_{\mathrm{o}}+\xi\right) \mathrm{H}(\xi) \mathrm{e}^{-\mathrm{j} 2 \pi \xi \mathrm{t}} \mathrm{d} \xi\right\} \\
& =\left|\mathrm{e}\left(v_{\mathrm{o}}, \mathrm{t}\right)\right| \cos \left(2 \pi v_{\mathrm{o}} \mathrm{t}+\phi\right)
\end{aligned}
$$


where

$$
\mathrm{e}\left(v_{\mathrm{o}}, \mathrm{t}\right)=\int_{-\infty}^{\infty} 2 \mathrm{a}\left(\nu_{\mathrm{o}}+\xi\right) \mathrm{E}\left(v_{\mathrm{o}}+\xi\right) \mathrm{H}(\xi) \mathrm{e}^{-\mathrm{j} 2 \pi \xi t} \mathrm{~d} \xi
$$

and where the assumption that $H(v)$ is nonzero only in a narrow band about $v_{0}$ (Equation A3) has been used to formally extend the lower limit of the integration in Equation A4 to infinity. From Equation A4 it is clear that $V(t)$ has the form of an amplitude modulated sinusoid, $\cos \left(2 \pi \nu_{\mathrm{o}} \mathrm{t}+\phi\right)$, at frequency $v_{0}$. The output of the detector is the envelope, $\left|e\left(v_{o}, t\right)\right|$, of this carrier. Thus, the output, $e_{o}(t)$ can be written:

$$
e_{o}(t)=\left|\int_{-\infty}^{\infty} 2 \mathrm{a}\left(v_{\mathrm{o}}+\xi\right) \mathrm{E}\left(v_{\mathrm{o}}+\xi\right) \mathrm{H}(\xi) \mathrm{e}^{-\mathrm{j} 2 \pi \xi \mathrm{t}} \mathrm{d} \xi\right|
$$

Now, suppose that over the narrow band of frequencies passed by the filter $\mathrm{a}\left(\nu_{\mathrm{o}}+\xi\right) \cong \mathrm{a}\left(\nu_{\mathrm{o}}\right)$ and $\mathrm{E}\left(\nu_{\mathrm{o}}+\xi\right) \cong$ $\mathrm{E}\left(v_{\mathrm{o}}\right)$. Then,

$$
e_{o}^{2}(t)=\left|E\left(v_{o}\right)\right|^{2} h^{2}(t)
$$

where $\left|\mathrm{E}\left(\nu_{\mathrm{o}}\right)\right|$ is the magnitude of the spectrum of the electric field at frequency $\nu_{\mathrm{o}}$ and where

$$
h(t)=\int_{-\infty}^{\infty} 2 \mathrm{a}\left(v_{\mathrm{o}}\right) \mathrm{H}(\xi) \mathrm{e}^{-\mathrm{j} 2 \pi \xi \mathrm{t}} \mathrm{d} \xi
$$

is the impulse response of the system. (Note: $\mathrm{e}^{2}=\mathrm{e} \mathrm{e}^{*}$ ) Integrating both sides of Equation A7 and using Parseval's theorem for Fourier transforms, one obtains:

$$
\begin{aligned}
\int_{-\infty}^{\infty} e_{0}^{2}(t) d t & =\left|E\left(v_{o}\right)\right|^{2} \int_{-\infty}^{\infty} h^{2}(t) d t \\
& =4\left|E\left(v_{o}\right)\right|^{2} \int_{-\infty}^{\infty}\left|a\left(v_{o}\right) H(\xi)\right|^{2} d \xi
\end{aligned}
$$

Finally, solving for the spectrum, one obtains:

$$
\left|E\left(v_{0}\right)\right|=\frac{1}{2 \sqrt{\Delta}} \sqrt{\int_{-\infty}^{\infty} e_{o}^{2}(t) d t}
$$

where

$$
\Delta=\left|\mathrm{a}\left(v_{\mathrm{o}}\right) \mathrm{H}(0)\right|^{2} \int_{-\infty}^{\infty} \frac{\mathrm{H}^{2}(\xi)}{\mathrm{H}^{2}(0)} \mathrm{d} \xi
$$

The integral in Equation A11 is commonly called the bandwidth (power bandwidth) of the system and $\left|a\left(v_{\mathrm{o}}\right) \mathrm{H}(0)\right|$ is the gain of the system. Equation A10 states that the spectrum of the input signal can be obtained by integrating the output and dividing by twice the gain times the square root of the bandwidth of the system. This result only 
applies to individual input signals, $\mathrm{E}(\mathrm{t})$, whose bandwidth is much larger than the bandwidth of the system (i.e. appear as impulses on the time scale of the impulse response of the system). This restriction is a consequence of factoring $E\left(v_{0}\right)$ out of Equation A6. If the input were a sequence of such pulses rather than an individual event $\mathrm{E}(\nu)$ in Equation A6 would be a sum of the form $\Sigma \mathrm{E}_{\mathrm{i}}(v) \mathrm{e}^{\mathrm{j} 2 \pi \nu \mathrm{t}_{\mathrm{i}}}$ where $\mathrm{E}_{\mathrm{i}}(v)$ is the spectrum of the individual pulses and $t_{i}$ is the time between pulses. In this case the spacing between pulses can affect the spectral estimate (Le Vine, 1977; Dennis and Pierce, 1964).

An important special case occurs when the system can be modelled as an ideal bandpass filter:

$$
H(\zeta)= \begin{cases}\mathrm{H}_{\mathrm{o}} & |\zeta|<\mathrm{B} / 2 \\ 0 & |\zeta|>\mathrm{B} / 2\end{cases}
$$

Then, from Equation A6 one obtains:

$$
\begin{aligned}
\mathbf{e}_{o}(t) & =2\left|a\left(\nu_{o}\right) E\left(\nu_{o}\right) H_{o} \int_{-B / 2}^{B / 2} \exp (-j 2 \pi v t) d v\right| \\
& =2\left|a\left(v_{o}\right) E\left(v_{o}\right)\right| H_{o} B \operatorname{sinc}(\pi B t) \\
& =e_{p} \operatorname{sinc}(\pi B t)
\end{aligned}
$$

where $e_{p}$ is the peak value of the signal out of the receiver. Now, squaring and integrating over all time, one obtains:

$$
\begin{aligned}
\int_{-\infty}^{\infty} e_{0}^{2}(t) d t & =e_{p}^{2} \int_{-\infty}^{\infty} \operatorname{sinc}^{2}(\pi B t) d t \\
& =e_{p}^{2} / B
\end{aligned}
$$

Finally, putting this result into Equation A10, one obtains:

$$
\left|E\left(v_{o}\right)\right|=\frac{e_{p}}{2 G B}
$$

where $G=\left|a\left(v_{0}\right) H(0)\right|$ is the gain of the system. Equation A15 applies only if the time between pulses is long compared to the response time of the system.

Another important special case occurs when the input is a random process. If the process consists of a sequence of identical pulses with random amplitude and/or arrival time, then the analysis proceeds as above with modifications as indicated in the text and described in detail by Le Vine (1977). However, if the random process is noise-like (i.e. a continuous, fluctuating signal), then the analysis must be modified. In this case, the appropriate definition of the spectrum, $S(v)$, is the Fourier transform of the autocorrelation function, $R(\tau)=<E(t) E^{*}(t+$ $\tau)>$ of the input signal. Assuming that the detector is an ideal square-law detector and that the input, $\mathrm{E}(\mathrm{t})$, is a stationary, ergodic random process, and defining $|\mathrm{E}(v)|=\sqrt{|\mathrm{S}(v)|}$, one obtains

$$
\left|E\left(v_{o}\right)\right|=\frac{1}{2 \sqrt{\Delta}} \sqrt{\frac{1}{2 T} \int_{-T}^{T} e_{o}^{2}(t) d t}
$$

where $\Delta$ is as defined in Equation $A 11$. In the casc of an ideal bandinass fillter (Equation A12), one has $\Delta=\mid \hat{a}^{\prime}\left(\dot{\nu}_{0}\right)$ $\left.\mathrm{H}(0)\right|^{2} \mathrm{~B}$. In this case, Equation A16 shows that $\left|\mathrm{E}\left(v_{\mathrm{o}}\right)\right|$ is proportional to $1 / \sqrt{\mathrm{B}}$ and can be obtained from the RMS 
value of the output signal by dividing by the square root of the bandwidth and twice the system gain. This result has been employed to compute spectra of lightning in some cases (e.g. Oh, 1969); however, as indicated in the text, lightning is intrinsically impulsive in nature and as a result this formula must be used with caution.
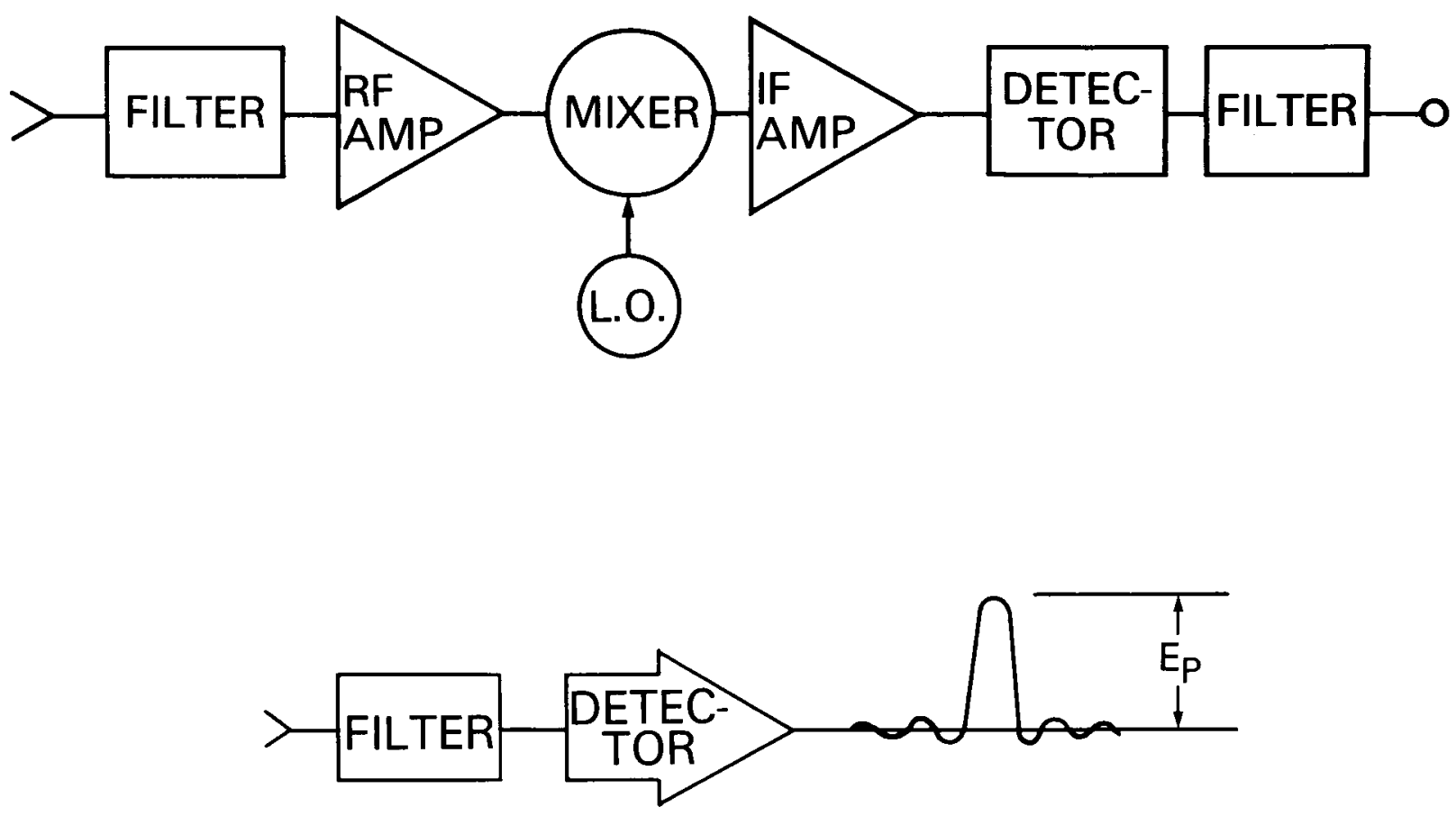

Figure A1. Example of a radio receiver used to measure spectrum of radiation from lightning. 
BIBLIOGRAPHIC DATA SHEET

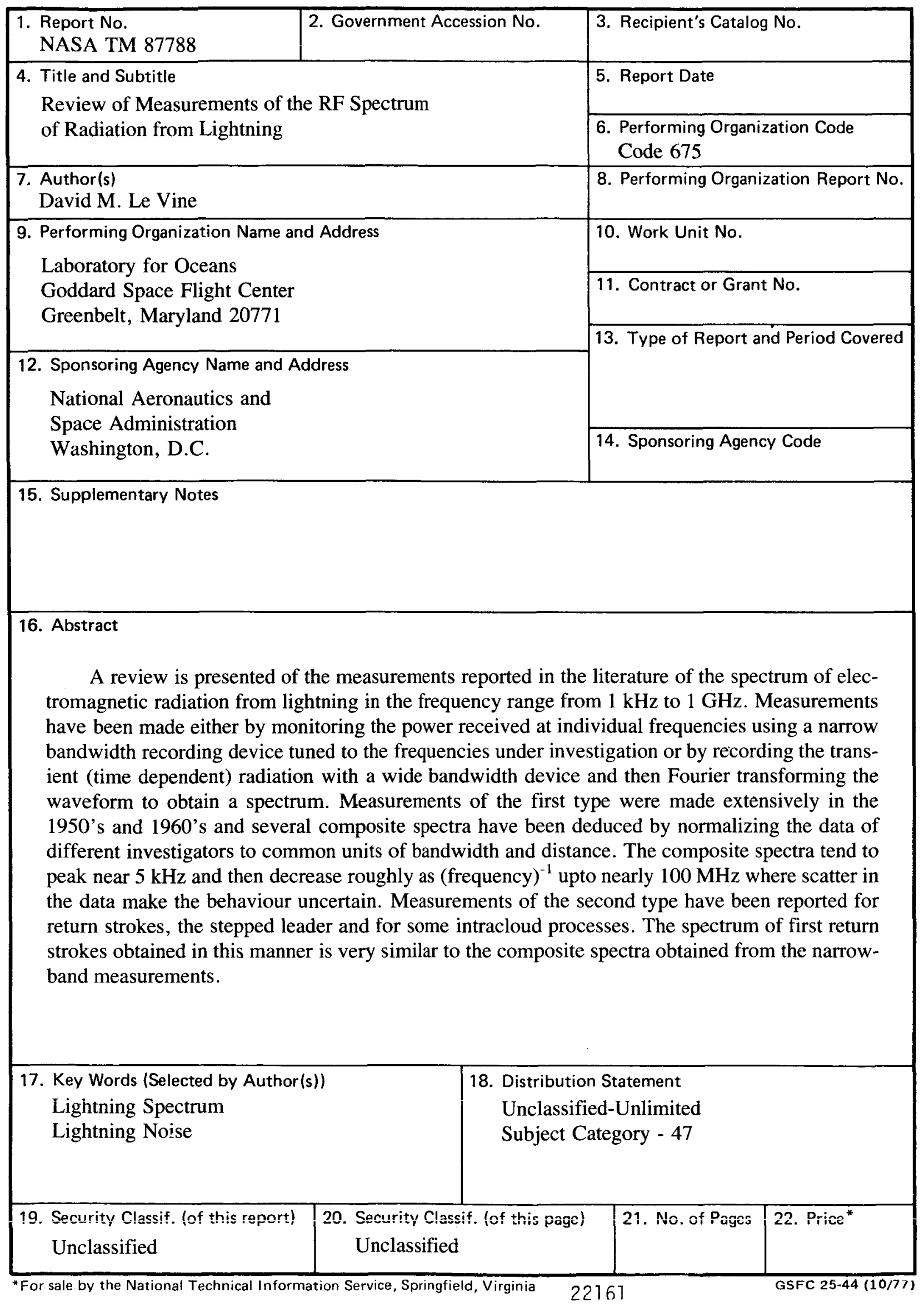

